\title{
THE INDUCTION OF "STRESS" PROTEINS IN ORGAN SLICES FROM BRAIN, HEART, AND LUNG AS A FUNCTION OF POSTNATAL DEVELOPMENT ${ }^{1}$
}

\author{
FREDRIC P. WHITE ${ }^{2}$ \\ Department of Biochemistry, Division of Basic Sciences, Faculty of Medicine, Memorial University of Newfoundland, St. John's, \\ Newfoundland, Canada A1B $3 V 6$
}

\begin{abstract}
The proteins synthesized in vitro by rat brain, heart, and lung slices were compared by twodimensional polyacrylamide gel electrophoresis. A protein, $\mathrm{P} 71$, which is related to one of the heat shock proteins induced in many cultured cells by hyperthermia and other harsh conditions, was the major protein synthesized by all slices from rats 3 weeks old and older. In vivo synthesis of P71 was not detected in brain, heart, or lung from these animals nor was there any detectable Coomassie brilliant blue-stained protein coinciding with P71 on the gels. P71 thus appears to be a minor protein species in normal unstressed brain, heart, and lung. While both heart and lung slices synthesized large quantities of P71 at all stages of postnatal development, brain slices synthesized little, if any, P71 until 3 weeks postnatal. There was a dramatic decrease in protein synthesis in all tissue slices during postnatal development. During this decrease, the relative abundance of newly synthesized P71 remained almost constant in heart and lung slices, but the relative abundance of P71 increased by approximately 50 -fold in brain slices. The cells synthesizing P71 in brain slices were enriched in a microvascular fraction. The increase in P71 synthesis by these cells, occurring between the 2nd and 3rd postnatal week, coincides with the final maturation of brain capillaries and the blood-brain barrier.
\end{abstract}

Most organs synthesize a protein with a molecular weight of 71,000 daltons (P71) in response to an unknown inducer after they are sliced and incubated in vitro (White, 1981a; Hightower and White, 1981). This protein also is synthesized by rat embryo cells in tissue culture in response to heat shock, canavanine, and heavy metal ions (Hightower and White, 1981) and by most organs in vivo after a 15-min episode of hyperthermia (Currie and White, 1981). P71 thus resembles one of the proteins which are induced by heat shock and other stressors in cells of Drosophila and other species (Tissieres et al., 1974; Kelley and Schlesinger, 1979; Hightower, 1980).

Brain was the first organ in which the synthesis of P71 by organ slices was detected (White, 1980a). The cells responsible for this synthesis were traced to the cerebral microvasculature (White, 1980a). Fractions enriched with microvessels from incubated slices contained up to 7 -fold higher concentrations of radioactive proteins than did their homogenates (White, 1979, 1980a, b). Since the protein synthesis of the brain, when measured either in

\footnotetext{
${ }^{1}$ This work was supported by Medical Research Council of Canada Grant MT-5405. I am grateful to Mrs. Norma Churchill for her excellent technical assistance.

${ }^{2}$ Present address: Department of Pharmacology, School of Medicine, University of Iowa, Iowa City, IA 52242.
}

vivo or in vitro, declines rapidly over the 1st month of growth (Lajtha et al., 1957; Orrego and Lipmann, 1967; Dunlop et al., 1975), I have examined the synthesis of P71 as a function of postnatal development in brain, heart, and lung slices to determine if its synthesis follows this general pattern.

\section{Materials and Methods}

Tissue slices were prepared from the telencephalon, heart, and lungs of male Sprague-Dawley rats as previously reported (White, 1979; Hightower and White, 1981). The slices were incubated in $5 \mathrm{ml}$ of a Krebs-Ringer phosphate buffer at $37^{\circ} \mathrm{C}$ for $30 \mathrm{~min}$ prior to the addition of $50 \mu \mathrm{l}$ of $\left[{ }^{3} \mathrm{H}\right]$ leucine $(110 \mathrm{Ci} / \mathrm{mmol}$, New England Nuclear, Lachine, PQ). After $2 \mathrm{hr}$, the incubated slices were washed with ice cold Ringer buffer to stop protein synthesis and to remove most of the unincorporated radioactivity. Some of the incubated slices were homogenized in $10 \mathrm{~mm}$ sodium phosphate buffer, $\mathrm{pH}$ 7.4. These homogenates were used to determine the incorporation of $\left[{ }^{3} \mathrm{H}\right]$ leucine into acid-precipitable protein as previously described (White, 1979). In other experiments, proteins synthesized in vivo were labeled by injecting $0.5 \mathrm{mCi}$ of $\left.{ }^{35} \mathrm{~S}\right]$ methionine $(400 \mathrm{Ci} / \mathrm{mmol}$, New England Nuclear) intraperitoneally. After $90 \mathrm{~min}$, the rats were anesthetized with sodium pentobarbital and perfused with cold 
saline through the left ventricle to remove as much albumin as possible (Currie and White, 1981).

Proteins were separated by two-dimensional electrophoresis according to the method of O'Farrell (1975). Briefly, slices were solubilized in a lysis buffer. Approximately $0.25 \mathrm{gm}$ of slices were solubilized in $1.0 \mathrm{ml}$ of lysis buffer. The samples were frozen and thawed three times and then stored at $-70^{\circ} \mathrm{C}$. Proteins were separated first by isoelectric focusing and then by sodium dodecyl sulfate-polyacrylamide gel electrophoresis (SDS-PAGE) as previously described (Currie and White, 1981). Radioactive proteins were detected by autofluorography by the method of Laskey and Mills (1975).

Microvessels were prepared from brain slices as previously described (White, 1980a). The vessels prepared ranged in size from small venules and arterioles to capillaries. Endothelial cells, pericytes, smooth muscle cells, and astrocyte end feet were still retained by most vessels (White et al., 1981).

\section{Results}

The incorporation of $\left[{ }^{3} \mathrm{H}\right]$ leucine into acid-precipitable protein in tissue slices as a function of age is shown in Figure 1. The rates of incorporation decreased drastically with age. The largest decrease was observed in brain slices where the incorporation decreased by 37 -fold during the first 6 weeks after birth. The heart slices showed a 20 -fold drop in incorporation during this period, while the decrease in lung slices was about 5 -fold. The rate of incorporation in all organ slices leveled off after 8 weeks. The lung slices always had the highest incorporation rates followed by brain and finally heart.

The major radioactive proteins found in the brain, heart, and lung after labeling with $\left[{ }^{35} \mathrm{~S}\right]$ methionine in vivo for $2 \mathrm{hr}$ are shown in Figures $2 A, 3 A$, and $4 A$, respectively. Albumin could be detected in all organs as a result of imperfect perfusion. If the organs were not perfused, albumin would overload during the SDSPAGE, masking many proteins. Among the newly synthesized proteins found in all organs were P73, P79, and actin. Unlike albumin, these are not found in the serum. They were easily detected among the stained proteins in the two-dimensional gels, indicating that they are major proteins in all three organs. The relative synthesis of these proteins in vivo was approximately equal to their relative concentration.

The proteins synthesized by the slices prepared from these organs (Figs. $2 F, 3 F$, and $4 F$ ) were altered drastically from those proteins synthesized in vivo. P71 was the major protein synthesized by all organ slices. It was not detectable in the in vivo pattern nor as Coomassie brilliant blue stain on the gels. It was not synthesized by any of these organ slices during the first $30 \mathrm{~min}$ of incubation and its synthesis by brain, heart, and lung slices was inhibited almost completely by actinomycin D (White, 1980a; Hightower and White, 1981). Unlike the other two organ slices, lung slices synthesized other proteins in detectable amounts, P73 and P79 among them.

The radioactive proteins synthesized by brain slices vary with postnatal development (Fig. $2, B$ to $F$ ). There was a dramatic decrease in the number of newly synthesized proteins which could be detected on the fluorograms as the age of the animals used to prepare the tissue

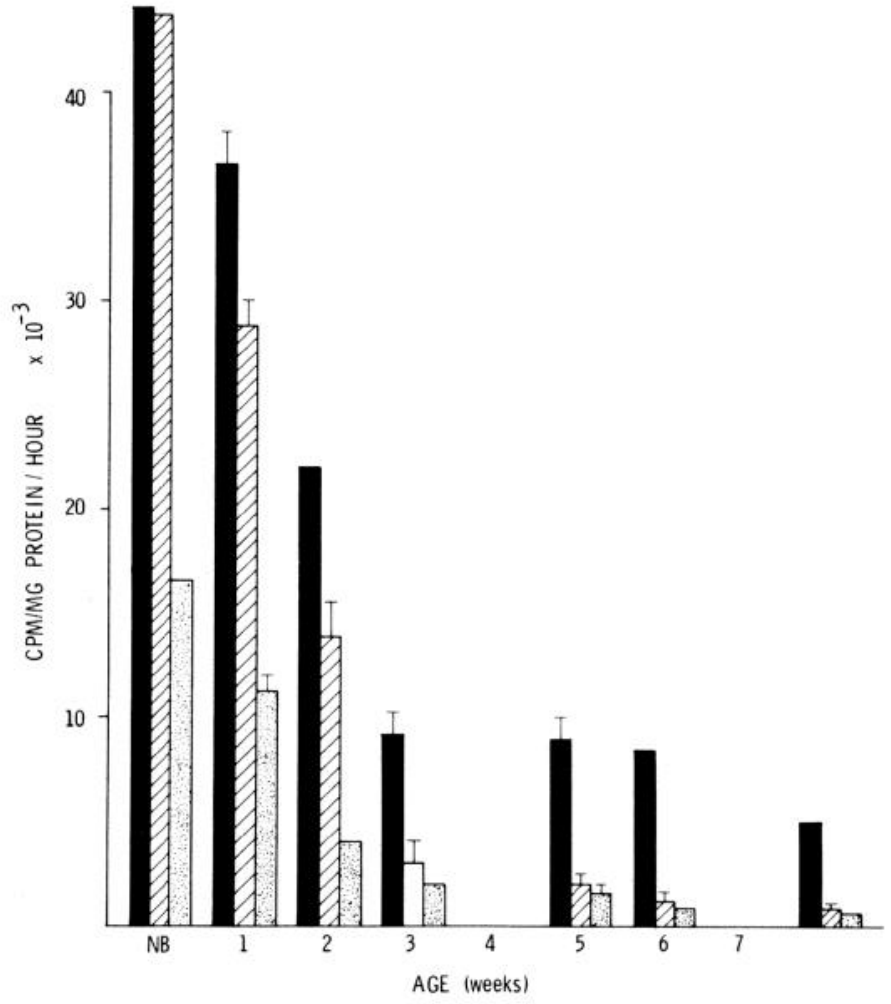

Figure 1. Incorporation of $\left[{ }^{3} \mathrm{H}\right]$ leucine into acid-precipitable protein by brain, heart, and lung slices as a function of postnatal age. Slices were prepared and incubated for $2 \mathrm{hr}$ in the presence of $10 \mu \mathrm{Ci} / \mathrm{ml}$ of $\left[{ }^{3} \mathrm{H}\right]$ leucine. The slices were homogenized. Protein and radioactivity were determined from aliquots of the homogenate (see "Materials and Methods"). All three organs were removed from the same animal for each determination. Error bars indicate the standard error of the mean $(n=3)$. Solid bar, lung; hatched bar, brain; stippled bar, heart. NB, newborn.

slices increased (Fig. 2, $E$ and $F$ compared to $B$ and C). This correlates well with the decrease in protein synthesis observed in Figure 1. Slices prepared from newborn rats synthesized large amounts of tubulin. The synthesis of tubulin decreased slowly over the first 8 days and was not detectable by 2 weeks. P73 was present in high amounts both as a radioactive and nonradioactive protein from day 1 . It showed the same general decrease in synthesis as tubulin, but it was always detectable. P71 was barely detectable at 1 day (Fig. $2 B$ ), 3 days, 7 days (Fig. $2 C$ ), 9 days, or 2 weeks (Fig. $2 D$ ) postnatal, but its synthesis increased at 3 weeks (Fig. $2 E$ ), and from this time on, it became the major protein synthesized by brain slices (Fig. $2 E$ ).

Unlike the brain, heart slices synthesized P71 in high amounts regardless of the age of the animal from which they were prepared. Heart slices from newborn rats synthesized $\mathrm{P} 71, \mathrm{P} 73$, and $\mathrm{P} 79$ at high rates (Fig. $3 B$ ). By day $8, \mathrm{P} 71$ was the major protein synthesized by heart slices (Fig. $3 C$ ). The relative synthesis of all proteins compared to $\mathrm{P} 71$ decreases with age (Fig. $3, B$ to $F$ ).

Lung slices, like heart slices, synthesized P71 at all times after birth (Fig. 4, $B$ to $F$ ). The synthesis of most other proteins decreased in comparison to P71 as a function of age. This was not the case, however, for P73 

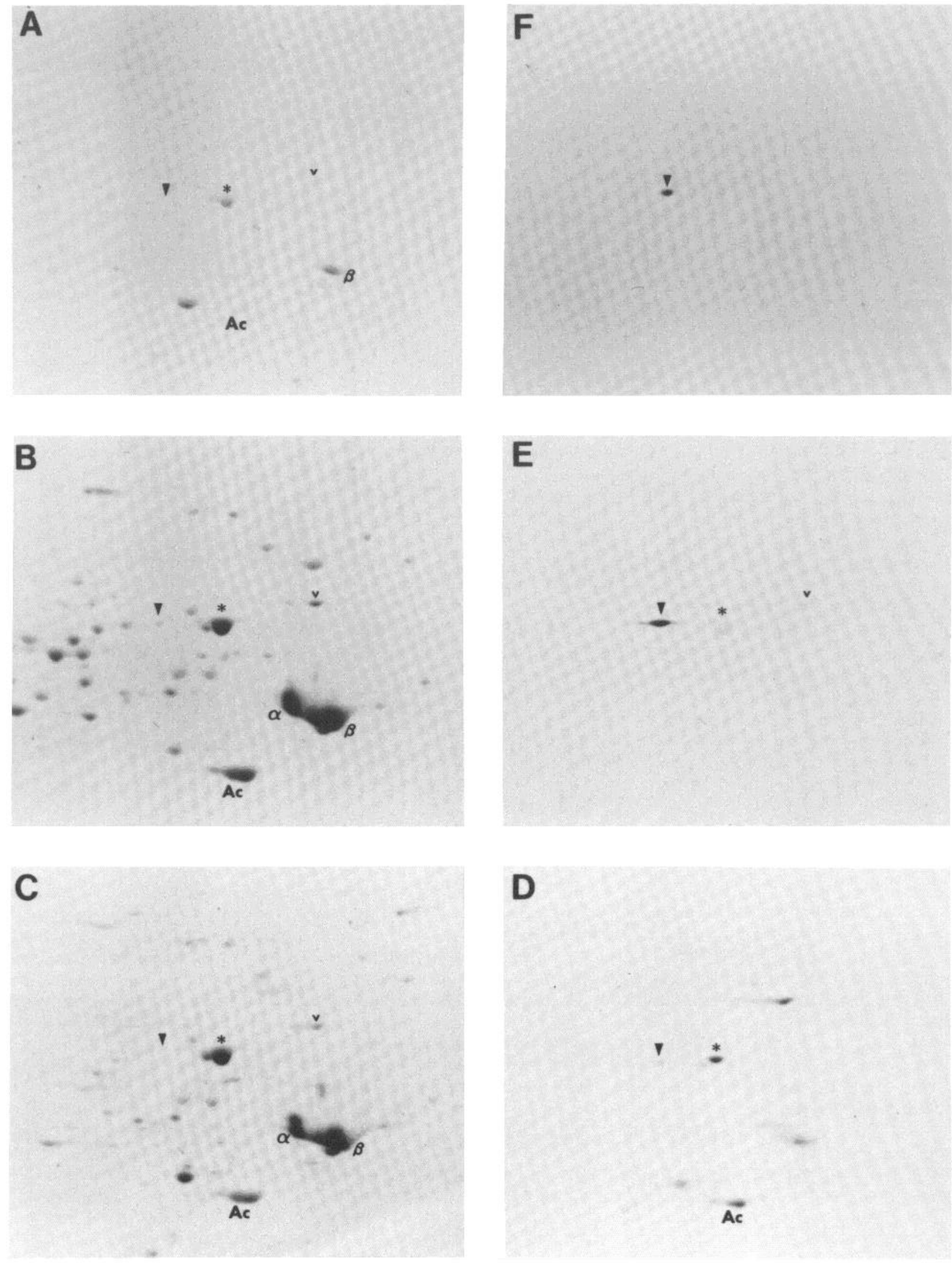

D

Figure 2. Proteins synthesized by the telencephalon in vivo and in vitro. Proteins synthesized in vivo were labeled for 2 hr by an intraperitoneal injection of $\left[{ }^{35} \mathrm{~S}\right]$ methionine. The rat was 8 weeks old at the time of injection. Proteins synthesized in vitro were labeled by incubating tissue slices for $2 \mathrm{hr}$ in a Ringer buffer supplemented with $\left[{ }^{3} \mathrm{H}\right]$ leucine. Proteins were separated by two-dimensional electrophoresis and radioactive proteins were detected by autofluorography. The following proteins are labeled on the fluorograms: actin $(A c), \mathrm{P} 71(\boldsymbol{\nabla}), \mathrm{P} 73(*), \mathrm{P} 79(v)$, and the two tubulins $(\alpha$ and $\beta)$. Proteins synthesized by the telencephalon of an 8-week-old rat in vivo $(A)$ and proteins synthesized by telencephalon slices in vitro 0 to 1 day postnatal $(B), 5$ to 7 days postnatal $(C), 2$ weeks postnatal $(D), 3$ weeks postnatal $(E)$, and 8 weeks postnatal $(F)$ are shown. 

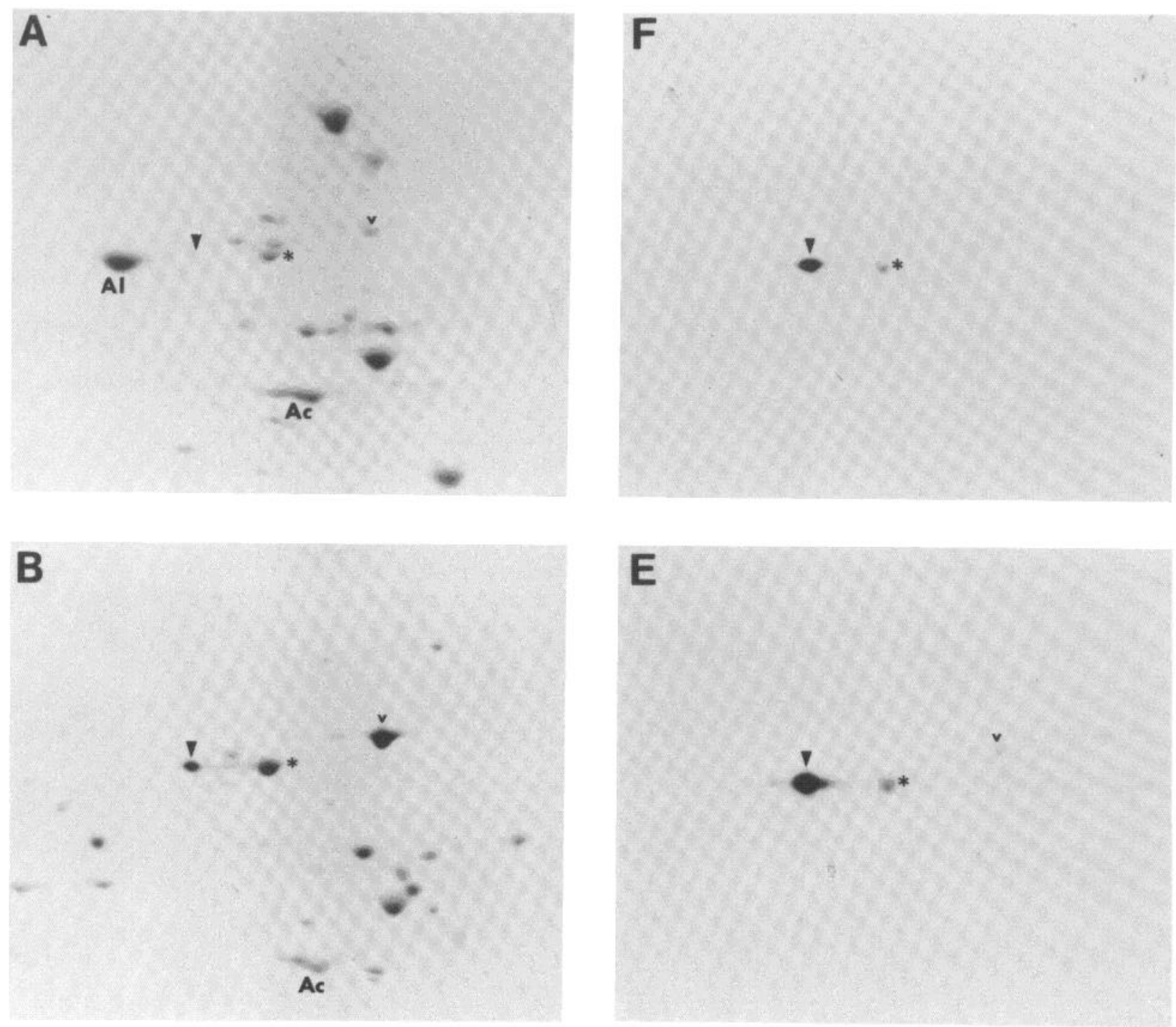

C

D

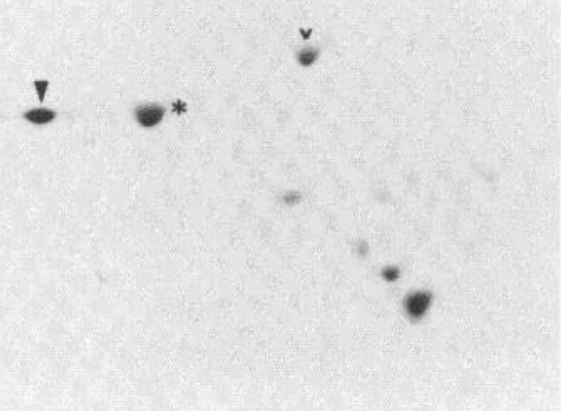

Figure 3. Proteins synthesized by the heart in vivo and in vitro. Proteins synthesized in vivo were labeled for 2 hr by an intraperitoneal injection of $\left[{ }^{35} \mathrm{~S}\right]$ methionine. The rat was 8 weeks old at the time of injection. Proteins synthesized in vitro were labeled by incubating tissue slices for $2 \mathrm{hr}$ in a Ringer buffer supplemented with [ $\left.{ }^{3} \mathrm{H}\right]$ leucine. Proteins were separated by twodimensional electrophoresis and radioactive proteins were detected by autofluorography. The following proteins are labeled on the fluorograms: actin $(A c)$, albumin $(A l)$, P71 $(\nabla)$, P73 (*), and P79 $(v)$. Proteins synthesized by the heart of an 8-week-old rat in vivo $(A)$ and proteins synthesized by heart slices in vitro 0 to 1 day postnatal $(B), 5$ to 7 days postnatal $(C), 2$ weeks postnatal $(D), 3$ weeks postnatal $(E)$, and 8 weeks postnatal $(F)$ are shown. 

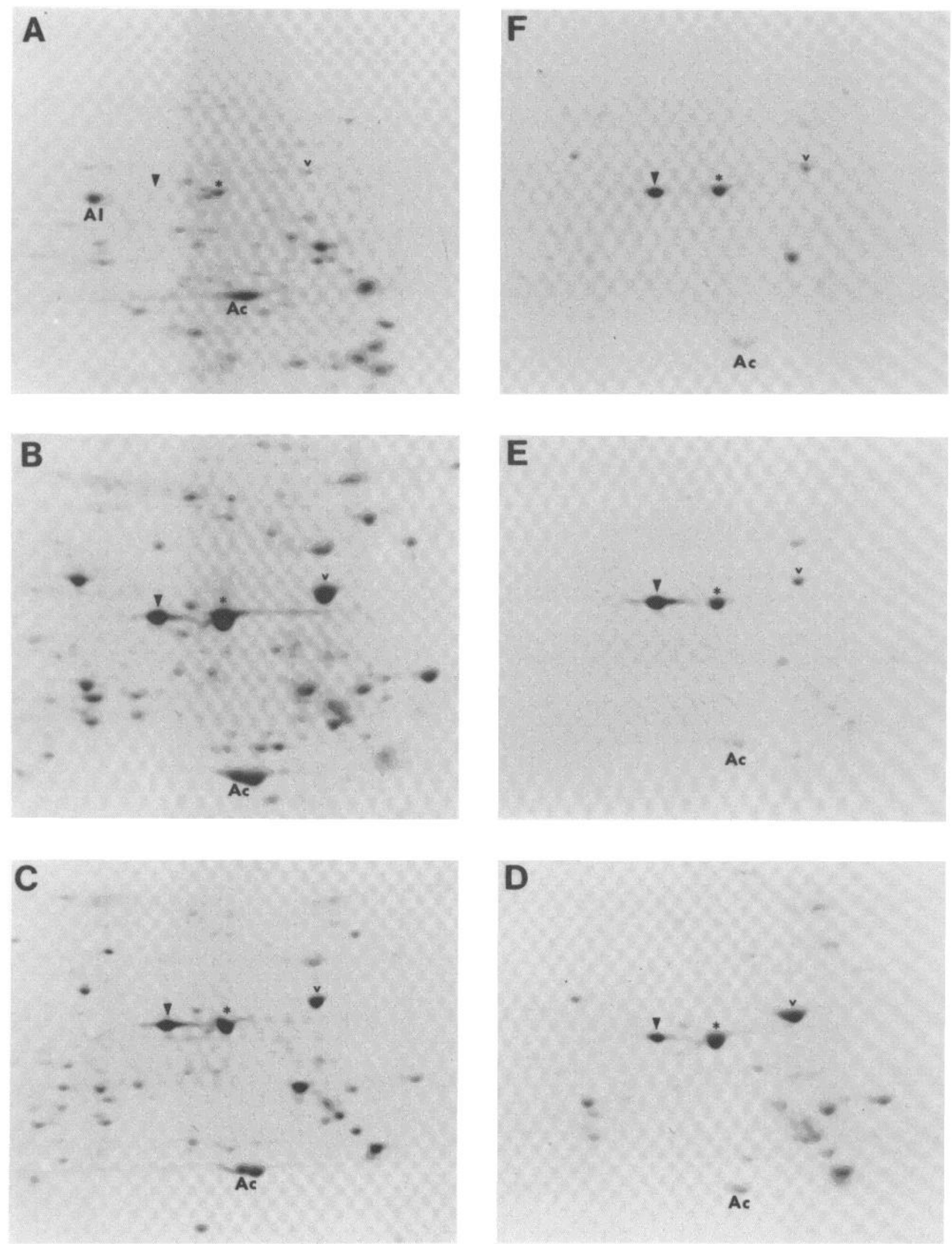

Figure 4. Proteins synthesized by the lung in vivo and in vitro. Proteins synthesized in vivo were labeled for 2 hr by an intraperitoneal injection of $\left[{ }^{35} \mathrm{~S}\right]$ methionine. The rat was 8 weeks old at the time of injection. Proteins synthesized in vitro were labeled by incubating tissue slices for $2 \mathrm{hr}$ in a Ringer buffer supplemented with $\left[{ }^{3} \mathrm{H}\right]$ leucine. Proteins were separated by twodimensional electrophoresis and radioactive proteins were detected by autofluorography. The following proteins are labeled on the fluorograms: actin $(A c)$; albumin $(A l)$, P71 $(\nabla)$, P73 (*), and P79 $(v)$. Proteins synthesized by the lung of an 8-week-old rat in vivo $(A)$ and proteins synthesized by lung slices in vitro 0 to 1 day postnatal $(B), 5$ to 7 days postnatal $(C), 2$ weeks postnatal $(D)$, 3 weeks postnatal $(E)$, and 8 weeks postnatal $(F)$ are shown. 
whose synthesis relative to $\mathrm{P} 71$ remained high at the ages tested.

In an effort to quantify these results, the optical densities of P71 and P73 were determined from fluorograms exposed for 2 weeks by a Corning model 750 scanning densitometer. In heart slices, the ratio of P71 to P73 increased from 0.64 in the newborn rat to 20 at 8 weeks, an approximate 30 -fold increase in the relative synthesis of P71. The radioactivity in P71 decreased by approximately 8-fold during this 8-week period. In lung slices, the decrease in radioactivity of P71 was approximately equal to the general decrease of incorporation by the slices (5-fold) and the change in the ratio of P71 to P73 was small ( 0.6 to 1.6$)$.

Brain slices, unlike heart and lung slices, did not synthesize appreciable quantities of P71 until 3 weeks. During postnatal development, the synthesis of $\mathrm{P} 71$ increased by approximately 10 -fold, while overall protein synthesis decreased by about 30 -fold. This was reflected in an approximately 250 -fold increase in the ratio of P71 to P73 which increased from 0.02 in the newborn to approximately 5 in older animals.

Since, in telencephalon slices prepared from mature rats, the synthesis of $\mathrm{P} 71$ has been shown to occur in the cells of the microvasculature, the very low synthesis of P71 found in brain slices prior to the 3rd postnatal week may reflect either a relatively small amount of microvascular protein synthesis occurring in young animals or an inability of microvascular elements to synthesize P71 before 3 weeks of age. To investigate these possibilities, microvessels were prepared from slices incubated for 2 hr with $\left[{ }^{3} \mathrm{H}\right]$ leucine as previously described (White, 1981b). All fractions were monitored by phase microscopy. The microvascular fractions prepared from rats older than 4 weeks had both a higher yield of vessels and a lower contamination from nonvascular cells. However, regardless of age, autoradiographs of the microvascular fractions showed that the microvessels were labeled intensely with radioactive proteins and that most of the radioactivity in each fraction was associated with vascular elements and not contaminants. The relative incorporation of radioactivity into proteins of the fractions enriched with microvessels, when normalized to their respective homogenates, was less in slices from young animals. This ratio increased with age from $0.337 \pm 0.078$ $(n=3)$ at 2 weeks to $2.11 \pm 0.16(n=4)$ at 4 weeks postnatal, and to $5.30 \pm 0.20(n=3)$ at 6 to 10 weeks postnatal. This 15 -fold increase in the relative incorporation of $\left[{ }^{3} \mathrm{H}\right]$ leucine into the protein of the microvasculature accounts for only part of the change in the relative abundance of radioactive P71. Figure 5 shows a comparison of the radioactive proteins found in the microvascular fractions and the soluble cytosol fractions at 2 and 6 weeks. The more than 10 -fold decrease in the incorporation of $\left[{ }^{3} \mathrm{H}\right]$ leucine into acid-precipitable proteins of the homogenate at 6 weeks is apparent in the decrease in the amount of radioactive proteins detected by autofluorography in the soluble cytosol fraction (Fig. 5). The rate of incorporation into the microvascular fraction decreased by only $50 \%$ during the same period. As seen in Figure 5, little if any P71 was detected in the microvascular fraction from slices at 2 weeks. However, P71 was

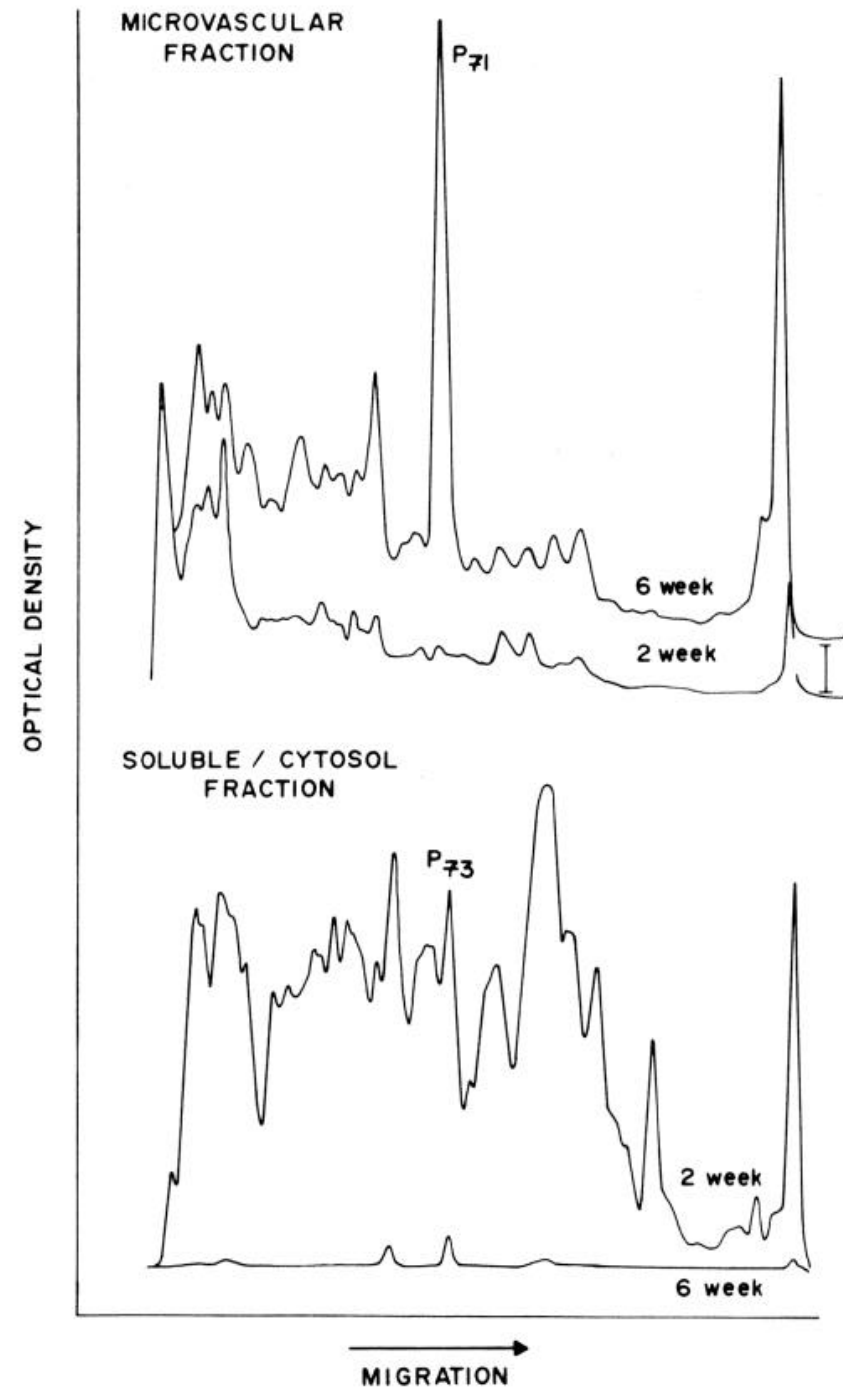

Figure 5. Comparison by sodium dodecyl sulfate-polyacrylamide gel electrophoresis of radioactive proteins accumulating in the microvascular fraction and cytosol soluble fraction from brain slices of 2- and 6-week-old rats. Samples were electrophoresed as previously described (White, $1980 \mathrm{~b}$ ) on a $7 \frac{1}{2} \%$ acrylamide slab gel. In this system, all proteins with a molecular weight less than 27,000 daltons are not separated and are coincident with the front. The samples were loaded in different wells on the same slab gel (soluble/cytosol fraction (6 week), $150 \mu \mathrm{g}$ of protein, $5,700 \mathrm{cpm}$; soluble/cytosol fraction (2week), $110 \mu \mathrm{g}$ of protein, $63,500 \mathrm{cpm}$; microvascular fraction ( 6 week), $130 \mu \mathrm{g}$ of protein, $8,000 \mathrm{cpm}$; and microvascular fraction (2 week), $70 \mu \mathrm{g}$ of protein, 7,900 cpm).

the major newly synthesized protein in the microvascular fraction at 6 weeks. There was an approximately 12 -fold increase in the amount of P71 found associated with microvessels over this 4 -week period (see Fig. 5). The relative synthesis of all proteins with a molecular weight less than 27 kilodaltons also increased in the microvascular fraction from 2 to 6 weeks. Figure 6 shows the radioactive proteins contained in the microvascular fractions at 2 and 6 weeks separated by two-dimensional electrophoresis. P71 was not synthesized by microvessels at 2 weeks but was the major product of protein synthesis at 6 weeks. Therefore, the ability to synthesize P71 in 

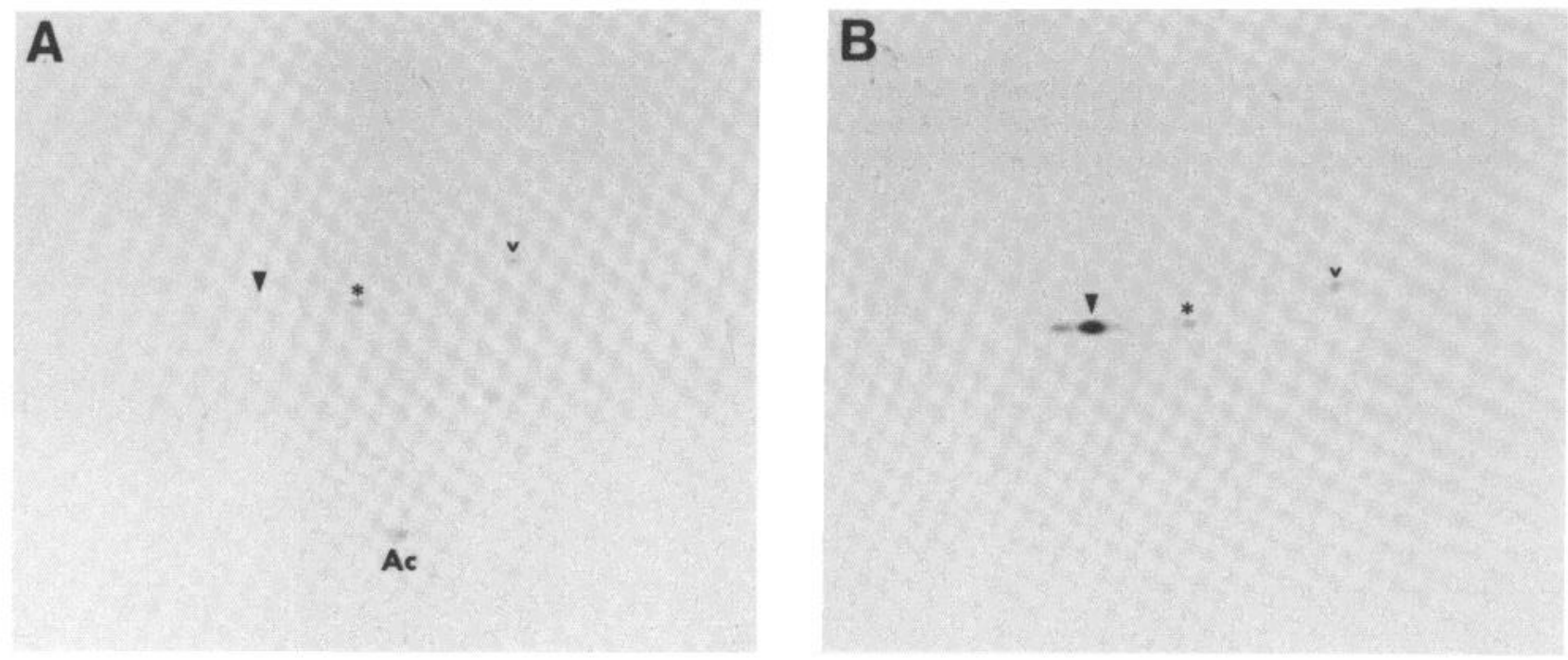

Figure 6. Comparison of radioactive proteins accumulating in cerebral microvascular fractions from brain slices of 2- and 6week-old rats. Proteins in the microvascular fractions described in Figure 5 and text were separated by two-dimensional electrophoresis and the radioactive proteins were detected by autofluorography (see Fig. 2 and "Materials and Methods"). $A$, Microvascular fraction from slices of 2 -week-old rats; $B$, microvascular fraction from slices of 6 -week-old rats. $A c$, actin; $\nabla$, P71; $*$, P73; $v$, P79.

response to tissue slicing was apparently absent in most brain cells, including those associated with microvessels, until approximately 3 weeks of age when some of the cells associated with the microvasculature developed a response already possessed by heart and lung cells at birth.

\section{Discussion}

A stress protein, P71, was found to be the major protein synthesized by brain slices prepared from animals at 3 weeks of age and older. However, in slices from younger animals, this protein was not detected. In contrast, P71 was found in large quantities in heart and lung slices prepared from all ages studied. The increase in the synthesis of P71 by brain slices observed between the 2nd and 3rd week of postnatal development appeared to occur in the cells associated with the cerebral microvessels. It has been shown previously that P71 is enriched in cerebral microvascular fractions and that P71 accumulates in these fractions when brain slices are incubated in either vinblastine, colchicine, or low calcium ion concentrations (White, 1980c). It also has been shown that isolated cerebral microvessels synthesize P71 in high amounts (White, 1980a). An autoradiographic study of the distribution of newly synthesized protein and RNA in brain slices from mature rats found that, while all cell types associated with the microvessels were labeled with ${ }^{3} \mathrm{H}$ protein, only the endothelial cell and pericyte were also labeled with $\left[{ }^{3} \mathrm{H}\right]$ RNA (White, 1981b). These studies support the hypothesis that, in brain slices, $\mathrm{P} 71$ synthesis occurs in microvessels and that the protein is exported from its site of synthesis to other intracellular or extracellular locations. The cells most likely responsible for both the synthesis and transport of P71 are the endothelial cell and pericyte, although the astrocyte and smooth muscle cell cannot be ruled out. Interestingly, the increased synthesis of P71 by cerebral microvessels in response to trauma corresponds very closely to the time at which these vessels reach structural (Donahue and Pappas, 1961; Bignami and Dahl, 1974; Boya et al., 1979) and functional (Joó et al., 1967; Orlowski and Meister, 1970; Betz and Goldstein, 1981) maturity. This period (between the 2nd and 3rd week of age) also coincides roughly with the maturation of the blood-brain barrier (Bradbury, 1979). Studies attempting to localize the cellular site of P71 synthesis in organs other than brain are currently in progress.

The overall protein synthesis by slices prepared from brain, heart, and lung decreased with age in this study. The decrease in the rate of incorporation of amino acids into proteins of the brain slice with age is a well known phenomenon (Orrego and Lipmann, 1967; Mokrasch and Manner, 1963; Dunlop et al., 1975). Accompanying this overall decrease in brain slice protein synthesis is an alteration in the type of cells which synthesize protein. Prior to 2 weeks, all cells are labeled with newly synthesized protein with the highest incorporation rates observed in neurons (Pavlik and Jakoubek, 1978). This distribution is altered markedly in slices from mature rats where few neurons are labeled compared to glial cells and cells associated with the microvasculature (Pavlík and Jakoubek, 1976, 1978; White, 1979, 1980b). This shift in incorporation was reflected in this study by the relative decrease in tubulin synthesis detected in brain slices and the relative increase in the accumulation of labeled proteins in microvascular fractions isolated from brain slices with increasing postnatal age.

\section{References}

Betz, A. L., and G. W. Goldstein (1981) Developmental changes in metabolism and transport properties of capillaries isolated from rat brain. J. Physiol. (Lond.) 321: 365-376.

Bignami, A., and D. Dahl (1974) Astrocyte-specific protein and neuroglial differentiation. An immunofluorescence study with antibodies to the glial fibrillary acidic protein. J. Comp. Neurol. 153: 27-38.

Boya, J., J. Calvo, and A. Prado (1979) The origin of microglial 
cells. J. Anat. 129: 177-186.

Bradbury, M. (1979) The Concept of a Blood-Brain Barrier, pp 289-310, John Wiley \& Sons, Inc., New York.

Currie, R. W., and F. P. White (1981) In vivo synthesis of a protein induced by heat stress. Science 214: 72-73.

Donahue, S., and G. D. Pappas (1961) The fine structure of capillaries in the cerebral cortex of the rat at various stages of development. Am. J. Anat. 108: 331-347.

Dunlop, D. S., W. VanElden, and A. Lajtha (1975) Optimal conditions for protein synthesis in incubated slices of rat brain. Brain Res. 99: 303-318.

Hightower, L. (1980) Cultured animal cells exposed to amino acid analogues or puromycin rapidly synthesize several polypeptides. J. Cell. Physiol. 102: 407-427.

Hightower, L., and F. P. White (1981) Cellular responses to stress: Comparison of a family of 71-73 kilodalton proteins rapidly synthesized in rat tissue slices and canavanine-treated cells in culture. J. Cell. Physiol. 108: 261-275.

Joó, F., T. Várkonyi, and B. Csillik (1967) Developmental alterations in the histochemical structures of brain capillaries: A histochemical contribution to the problem of the bloodbrain barrier. Histochemie 9: 140-148.

Kelley, P., and M. Schlesinger (1979) The effect of amino acid analogues and heat shock on gene expression in chicken embryo fibroblasts. Cell 15: 1277-1286.

Lajtha, A., S. Furst, A. Gerstein, and H. Waelsch (1957) Amino acid and protein metabolism of the brain. I. Turnover of free and protein bound lysine in brain and other organs. J. Neurochem. 1: 289-300.

Lasky, R. E., and A. D. Mills (1975) Quantitative film detection of ${ }^{3} \mathrm{H}$ and ${ }^{14} \mathrm{C}$ in polyacrylamide gels by fluorography. Eur. J. Biochem. 56: 335-341.

Mokrasch, L. C., and P. J. Manner (1963) Incorporation of ${ }^{14} \mathrm{C}$ amino acids and ${ }^{14} \mathrm{C}$ palmitate into proteolipids of rat brains in vitro. J. Neurochem. 10: 541-547.

O'Farrell, P. H. (1975) High resolution two-dimensional electro- phoresis of proteins. J. Biol. Chem. 250: 4007-4021.

Orlowski, M., and A. Meister (1970) The $\gamma$-glutamyl cycle: A possible transport system for amino acids. Proc. Natl. Acad. Sci. U. S. A. 67: 1248-1255.

Orrego, F., and F. Lipmann (1967) Protein synthesis in brain slices. J. Biol. Chem. 242: 665-671.

Pavlík, A., and B. Jakoubek (1976) Distribution of proteinbound radioactivity in brain slices of adult rat incubated with labelled leucine. Brain Res. 101: 113-128.

Pavlík, A., and B. Jakoubek (1978) Developmental changes of protein-bound radioactivity distribution in rat brain slices incubated with labelled leucine. Brain Res, 154: 95-104.

Tissieres, A., H. Mitchell, and V. Traeg (1974) Protein synthesis in salivary glands of Drosophilia melanogaster: Relation to chromosome puffs. J. Mol. Biol. 84: 389-398.

White, F. P. (1979) Subcellular particles involved in the translocation of proteins in rat brain. J. Neurobiol. 10: 591-607.

White, F. P. (1980a) Differences in protein synthesized in vivo and in vitro by cells associated with the cerebral microvasculature. A protein synthesized in response to trauma? Neuroscience 5: 1793-1799.

White, F. P. (1980b) Protein synthesis in rat telencephalon slices: High amounts of newly synthesized protein found in association with brain capillaries. Neuroscience 5: 173-178.

White, F. P. (1980c) The synthesis and transport of specific proteins by cells associated with brain capillaries. J. Neurochem. 35: 88-94.

White, F. P. (1981a) Synthesis of "stress" proteins by tissue slices from brain and other organs. Trans. Am. Soc. Neurochem. 12: 261.

White, F. P. (1981b) Protein and RNA synthesis in cerebral microvessels: A radioautographic study. Brain Res., in press.

White, F. P., G. R. Dutton, and M. D. Norenberg (1981) Microvessels isolated from rat brain: Localization of astrocyte processes by immunohistochemical techniques. J. Neurochem. 36: 328-332. 